\title{
Rapid Expression of Heat Shock Protein in the Rabbit after Brief Cardiac Ischemia
}

Anne A. Knowiton, Peter Brecher, and Carl S. Apstein

With the technical assistance of Soeun Ngoy and Gabriel M. Romo

Cardiac Muscle Research Laboratory, Whitaker Cardiovascular Institute, and the Biochemistry Department, Boston University School of

Medicine, and the Cardiology Section and the Thorndike Memorial Laboratory, Boston City Hospital, Boston, Massachusetts 02118

\begin{abstract}
The effect of brief myocardial ischemia on the expression of heat shock protein (HSP 70) was examined in an in vivo rabbit model of myocardial ischemia using Northern blotting. Functional studies were carried out in the open-chested anesthetized rabbit. The large marginal branch of the left circumflex was occluded four times for $5 \mathrm{~min}$. Using piezoelectric crystals implanted midwall in the ischemic zone, end-diastolic length, endsystolic length, and percent segmental shortening were assessed. Expression of HSP 70 was measured by Northern blotting. A single 5-min coronary occlusion doubled the expression of HSP 70 whereas four cycles of $5 \mathrm{~min}$ of ischemia/5 min of reperfusion resulted in a threefold increase in HSP 70 mRNA $(P<0.001)$. Measurements with the piezoelectric crystals showed mild myocardial dysfunction concomitant with the increase in HSP 70. This increase in HSP 70 mRNA after repetitive brief ischemia was transient, occurring as early as $1 \mathrm{~h}$ and returning to baseline by $24 \mathrm{~h}$ after ischemia. Western blot analysis with a monoclonal antibody to HSP 70 was used to compare sham and postischemic myocardial HSP 70 levels. Changes in the amount of HSP 70 were evident as early as $2 \mathrm{~h}$ and were even more striking at 24 h. (J. Clin. Invest. 1991.87:139-147.) Key words: angina - gene induction - myocardial infarction • myocardial stunning $\bullet$ reperfusion
\end{abstract}

\section{Introduction}

Repetitive brief ischemia has been shown to have prolonged effects on hemodynamic function and high-energy phosphate levels (1-7). This combination of reduced high-energy phosphates and depressed hemodynamic function has been termed "stunning" (8). A protective effect of brief ischemia preceding prolonged ischemia has also been described, and this has been termed "preconditioning" (4). Although the effects of stunning and preconditioning have been well described, the mechanisms remain elusive. We postulated that even a brief episode of ischemia, the experimental equivalent of an anginal episode, might have an effect on gene expression, and that altered gene expression could have a role in myocardial stunning and precondi-

This study was presented in part at the American Heart Association Scientific Sessions, New Orleans, LA, November 1989.

Address reprint requests to Dr. Knowlton, Boston University School of Medicine, R-215, 80 East Concord Street, Boston, MA 02118.

Received for publication 3 October 1989 and in revised form 10 July 1990.

J. Clin. Invest.

(C) The American Society for Clinical Investigation, Inc.

0021-9738/91/01/0139/09 \$2.00

Volume 87, January 1991, 139-147 tioning. A likely change would be an increase in the expression of the major heat shock protein, HSP $70,{ }^{1}$ as heat shock proteins are expressed in response to numerous stresses in other tissues and organisms $(9,10)$. HSP 70 has been observed to increase in the heart in response to prolonged ischemia of sufficient duration to result in infarction (11) and in response to pressure overload $(12,13)$. The induction of HSP 70 in pressure overload occurs simultaneously with the induction of the proto-oncogenes, c-myc and c-fos (13) and precedes the induction of the genes for the fetal isoforms of the contractile proteins. Cell cycle-dependent changes in HSP 70 expression in cell culture (HeLa cells) have raised the possibility that this protein has a role in regulation of cell growth (14). In addition, HSP 70 has been shown to be preferentially translated to the exclusion of other mRNAs, raising the possibility that its expression might have a direct role in stunning by effectively inhibiting the translation of other proteins $(9,10,15)$.

Although the majority of studies of myocardial stunning have focused on the canine model, there have been studies in other species, such as the pig (16) and ferret (17). A previous study from our laboratory examined repetitive ischemia in the isolated blood-perfused rabbit heart. In those studies, stunning, characterized by depressed systolic and diastolic function, was observed after four cycles of $5 \mathrm{~min}$ of ischemia/5 min of reperfusion (18). To examine this phenomena in a more physiologic in vivo model, New Zealand white rabbits were subjected to brief cardiac ischemia and reperfusion. Function was assessed using piezoelectric crystals implanted in the myocardial wall and HSP 70 expression was determined by measuring steadystate mRNA levels and by Western blot analysis.

\section{Methods}

Male New Zealand white rabbits, $1.5-2.5 \mathrm{~kg}$ in size, were used for all studies. For studies of normal tissue, the rabbits were overdosed with intravenous pentobarbital, $75 \mathrm{mg} / \mathrm{kg}$, and the hearts were immediately removed, dissected, and frozen in liquid nitrogen. Time from removal to freezing was $<30 \mathrm{~s}$. For studies of ischemia, rabbits were anesthetized with intravenous pentobarbital, intubated, and then mechanically ventilated as previously described (19). Xylocaine was used as an additional local anesthetic during the initial surgical procedure. All rabbits received $3 \mathrm{ml}$ of a $1 \%$ solution subcutaneously. Thoracotomy was performed and a silk snare was placed around the large marginal branch of the circumflex artery midway between the atrioventricular groove and the apex. Ischemia was induced by tightening the snare for 5 min with a clamp and releasing it. Ischemia and reperfusion were verified in these experiments by visual inspection. All rabbits had a carotid artery catheter placed for monitoring systemic pressure. 42 rabbits underwent these protocols. They were divided into two groups. One group ( 12 rabbits) underwent more detailed measurement of function as described below. 30 rabbits were used for biochemical measure-

1. Abbreviations used in this paper: G3PD, glyceraldehyde-3-phosphate dehydrogenase; HSP, heat shock protein. 
ments. There was one operative death. Two rabbits were excluded because they developed brief ventricular fibrillation during one of the reperfusion cycles.

To assess the effect of repetitive ischemia in the in vivo rabbit heart, a pair of 5-MHz piezoelectric crystals were placed in the ischemic zone perpendicular to the main axis of the heart. The crystals, which were of $1 \mathrm{~mm}$ diam, were placed in the midwall of the left ventricle $5-12 \mathrm{~mm}$ apart (Fig. 1). For most of the studies only a single pair of crystals was used because of the small size of the rabbit heart. In two rabbits a second pair of crystals was placed in the nonischemic region of the left ventricle perpendicular to the main axis of the heart. Signal from the crystals was monitored using a dual-beam oscilloscope (Tektronics, Inc., Beaverton, OR), and output from a sonomicrometer (model 120 , Triton Technology, San Diego, CA), was recorded by mean of a fourchannel recorder (Gould, Inc., Cleveland, $\mathrm{OH}$ ). An intramyocardial electrocardiogram was obtained from the crystals and recorded on a separate channel. The systemic pressure, systolic, diastolic, and mean were recorded on a third channel. The recorder was run at $0.05-50$ $\mathrm{mm} / \mathrm{s}$ throughout the experiment. Using this method systemic pressure, heart rate, end-diastolic length, end-systolic length, and segmental shortening were determined. Measurements were made at baseline, and at $1 \mathrm{~min}$ and $4 \mathrm{~min} 45 \mathrm{~s}$ of each ischemia and reperfusion cycle. All hearts on visual inspection were clearly ischemic in the region of the crystals after occlusion as evidenced by visual cyanosis and visual hypokinesis to dyskinesis. The segment length changes during ischemia demonstrated severe hypokinesis to dyskinesis. In addition, ST segment elevation was evident on electrocardiogram. After the four cycles of ischemia and reperfusion, the chest was closed and monitoring of all parameters continued for another $3 \mathrm{~h}$. During the first hour of recovery measurements were made every $10 \mathrm{~min}$. Thereafter measurements

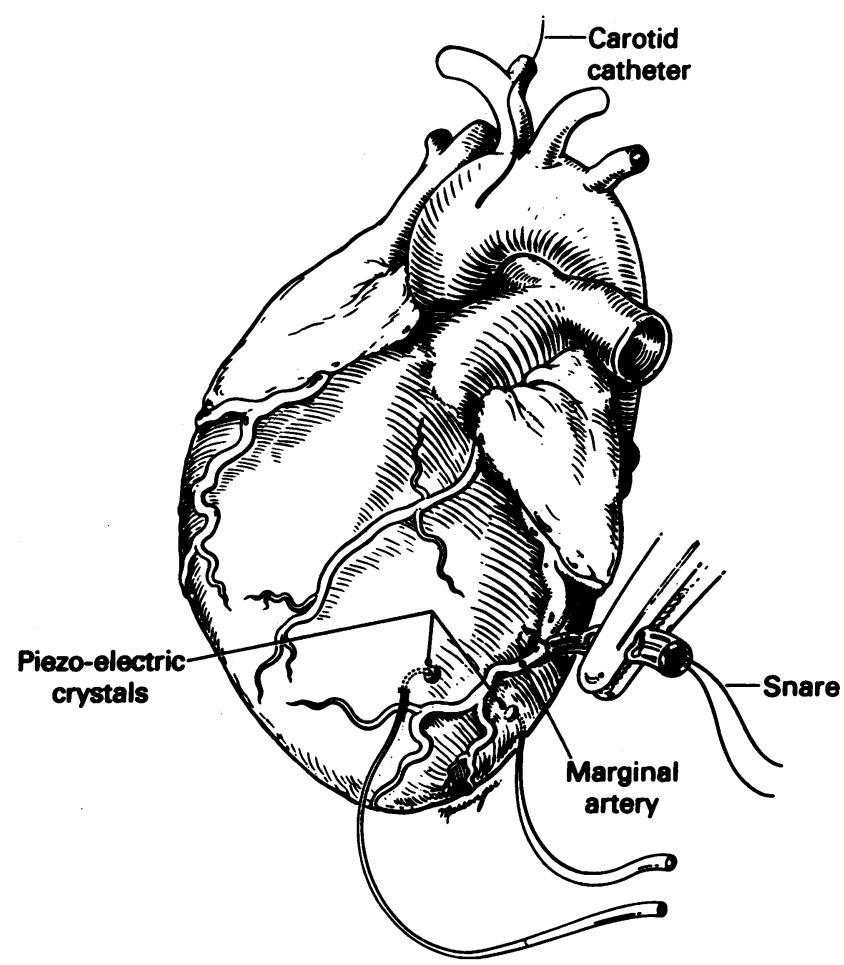

Figure 1. Illustration of the study preparation. An arterial line in carotid artery was used for measurement of systemic pressure. A snare was placed around the large marginal branch of the circumflex artery. A pair of 5-mHz piezoelectric crystals was implanted in the midmyocardial wall in the ischemic zone. In two rabbits an additional pair was placed in the nonischemic region of the ventricle. Segment length measurements were made from these crystals and segmental shortening was calculated from these values. were made every $15 \mathrm{~min}$. At $3 \mathrm{~h}$, the rabbits were overdosed with pentobarbital, the hearts were removed, and the position of the crystals was verified. Hearts were then sliced breadloaf fashion and stained with nitroblue tetrazolium as previously described to exclude any necrosis (19-21). In two rabbits placement of the crystals was technically diffcult and complicated in one by a small branch arterial bleed and in another by clear occlusion of a branch vessel when the crystal was sutured in place. Both of these hearts had small infarcts distal to the crystals by nitroblue tetrazolium stain, and were therefore excluded from analysis. In two rabbits in the last hour of monitoring, the signal from the crystals could not be fully analyzed secondary to artifact.

End-diastolic and end-systolic lengths were determined from the strip chart recording. End diastole was timed from the onset of the QRS and end systole from the dicrotic notch. Segmental shortening was calculated by the following equation $(E D L=$ end-diastolic length, $E S L$ $=$ end-systolic length, and $S S=$ segmental shortening $): 100 \times(E D L$ $E S L) / E D L=\% S S$

The velocity of shortening $(\mathrm{d} L / \mathrm{d} t)$ was derived from the segment length recordings on three to five consecutive beats, and was expressed as a percentage of the baseline value because of the variability among individuals.

For the biochemical studies both four cycles of $5 \mathrm{~min}$ of ischemia/5 min of reperfusion and a single 5-min occlusion with reperfusion were examined. At the completion of the protocol the snare was left loosely in place to mark its position, and the chest was closed. $2 \mathrm{~h}$ later the rabbits were overdosed with pentobarbital and the hearts were removed as described above. Tissue samples from the ischemic zone, immediately below the snare, and the nonischemic zone, the upper left ventricular free wall, and septum were frozen rapidly in liquid nitrogen. Additional groups subjected to repetitive ischemia were overdosed at 1,4 , and $24 \mathrm{~h}$ to determine the time course of acute changes in mRNA levels. In two rabbits the heart was removed after coronary occlusion for $2 \mathrm{~h} 35 \mathrm{~min}$. This matched the total time course for the $5 \mathrm{~min} \times 4$ protocol followed by $2 \mathrm{~h}$ of reperfusion (i.e., the 2-h group).

Four sham-operated controls underwent the same surgical protocol as the experimental group, including incising the pericardium, except no coronary occlusion was done. Two of the four had a snare placed in the myocardium. The chests were left open for $35 \mathrm{~min}$, the same duration as with the repetitive ischemia protocol, and the rabbits were overdosed $2 \mathrm{~h}$ after completion of the sham protocol. This was done to determine whether a change in mRNA levels was induced by anesthesia or surgical manipulation of the heart. Direct comparison of the sham-operated hearts with normal ventricles showed there was no change in expression of HSP 70 mRNA.

$R N A$ isolation and analysis. These procedures were performed using the guanidinium thiocyanate/cesium chloride centrifugation method of Chirgwin et al. (22) with slight modification. For Northern blot analysis, total cellular RNA was separated electrophoretically as previously described (23). Northern blotting was performed by vacuum transfer (Stratavac, Stratagene, New Haven, CT) in $1.5 \mathrm{M} \mathrm{NaCl} / 1.5 \mathrm{M}$ sodium citrate, pH 7 (10× SSC), to a nylon membrane (Genescreen, Dupont/New England Nuclear, Boston, MA). After transfer, the membrane was washed in $0.3 \mathrm{M} \mathrm{NaCl} / 0.3 \mathrm{M}$ sodium citrate, $\mathrm{pH} 7,(2 \times \mathrm{SSC})$ and UV cross-linking was performed using a Stratalinker apparatus (Stratagene). Prehybridization was carried out as recommended by the manufacturer of the nylon membrane. Hybridization was then performed overnight using cDNA probes labeled by random hexamer priming with $\left[{ }^{32} \mathrm{P}\right] \mathrm{dCTP}$ using a commercial kit (Amersham Corp., Arlington Heights, IL). After hybridization, membranes were washed with $1 \%$ SDS and $0.15 \mathrm{M} \mathrm{NaCl} / 0.15 \mathrm{M}$ sodium citrate, $\mathrm{pH} 7(1 \times \mathrm{SSC})$, for $10 \mathrm{~min}$ at 52 to $55^{\circ} \mathrm{C}$ and then for $2 \mathrm{~min}$ at $52-55^{\circ} \mathrm{C}$. Blots were exposed to preflashed X-Omat film (Eastman Kodak Co., Rochester, $\mathrm{NY}$ ) at $-70 \mathrm{C}$. Laser densitometry was performed when appropriate.

Dot blot analysis. This procedure was performed using a dot blotting apparatus (BioRad Laboratories, Richmond, CA). 2, 5, and $10 \mu \mathrm{g}$ of RNA was applied to nylon membranes (Genescreen). Membranes were washed in $2 \times$ SSC and then cross-linked as described above. Hybridization was carried out as described above for Northern blot analy- 
sis, using 25-50 ng of the cDNA for individual hybridizations. Dot blot analysis was performed initially with the cDNA for HSP 70. Subsequently the membranes were treated to remove residual cDNA and hybridized sequentially with cDNA probes for collagen $\alpha 1$ (IV) and glyceraldehyde-3-phosphate dehydrogenase (G3PD), which were used as controls for quantitation. Laser densitometry with a computing densitometer (Molecular Dynamics, Sunnyvale, CA) was used to quantitate changes in HSP 70 mRNA levels and these results were normalized relative to the signal obtained for the collagen $\alpha 1$ (IV) cDNA and for the G3PD cDNA. This resulted in only minor changes in the measured values obtained directly for HSP 70 .

cDNA. The cDNA for HSP 70 was the 2.3-kb BamHI/Hind III fragment of pH 2.3 (American Type Culture Collection, Rockville, MD) and has been described previously $(24,25)$. The EcoRI/Hind III 1.1-kb fragment of PE123 for collagen $\alpha 1$ (IV) (26) and the Hind III/ Xbal 500-bp fragment of pUC13 for G3PD (27) were used as controls.

Gel electrophoresis and western blotting. A cytosolic extract of cardiac tissue was prepared as previously described (28). Briefly, tissue was homogenized in $0.1 \mathrm{M}$ phosphate buffer in the presence of protease inhibitors and then centrifuged at $18,600 \mathrm{~g}$ for $30 \mathrm{~min}$. The supernatant, which represents cytosolic protein, was aliquoted and stored at $-70^{\circ} \mathrm{C}$ until use. Protein concentrations were measured using the bicinchoninic acid (BCA) assay (Pierce Chemical Co., Rockford, IL) with bovine serum albumin as a standard. Samples were then analyzed by SDS-PAGE. Final adjustments in sample amounts were made by visually comparing the actin band in each lane after staining with Coomassie Blue. This was done to correct for serum albumin contamination, which differed between samples, and to normalize for intracellular protein between samples. Two-dimensional electrophoresis was used before immunoblotting to clearly separate albumin from the intracellular HSP 70. Ampholyte mixtures containing pH 5-7 and 3-7 were used at a ratio of 2.5:1. 12\% SDS-PAGE was used in the second dimension and subsequent transfer to nitrocellulose was done at $25 \mathrm{~V}$ overnight at $4^{\circ} \mathrm{C}$. All gels were run in duplicate to confirm satisfactory sample separation.

Immunoblotting was performed using a monoclonal antibody to HSP 72 (mouse monoclonal, anti-HSP 72, Amersham Corp.). This antibody was originally developed (29) against HSP 72 from HeLa cells (30). In a recent study Milarski et al. (14) stated that their respective HSP 70 and HSP 72 are the same protein. Thus the antibody and the cDNA are measuring protein and mRNA levels for the same gene. Using this antibody, the blot was developed as previously described using the anti-HSP 72 antibody in a 1:1,000 dilution and an alkaline phosphatase anti-mouse Ig (Promega Biotec, Madison, WI) in a 1:2,000 dilution for the second antibody.

Statistical comparison of the hemodynamic data was done using an analysis of variance for repeated measures followed by the StudentNeuman-Keuls test. Laser densitometry results were analyzed using an analysis of variance and the Student $t$ test. A $P<0.05$ was considered significant. All numbers are reported as mean \pm SEM unless stated otherwise.

\section{Results}

Hemodynamic studies. The mean baseline segmental systolic shortening was $11.0 \pm 0.8 \%$ of end-diastolic length. Initial mean aortic pressure was $82.1 \pm 4.4 \mathrm{~mm} \mathrm{Hg}$ with a heart rate of $231 \pm 6$ beats/min. These and selected subsequent measurements are summarized in Table I. Fig. 2 shows a representative sample of the tracings obtained during one experiment. As the segmental shortening varied among individuals, these data were expressed as a percentage of baseline for comparison and statistical analysis. All hearts showed severe hypokinesis to dyskinesis with ischemia, with a prompt recovery with reperfusion as illustrated in Fig. 3. During the ischemic periods the segmental shortening was significantly depressed as shown $(P<0.05$ for all points). There was no significant difference between baseline segmental shortening and segmental shortening during any of the periods of reperfusion either expressing data as raw numbers or as percentage of baseline function.

As the distance between crystals varied, both end-diastolic and end-systolic lengths were analyzed as percentage of base-

Table I. Functional Effects of Repetitive Ischemia and Reperfusion

\begin{tabular}{|c|c|c|c|c|c|c|c|c|c|c|c|c|}
\hline \multirow[b]{2}{*}{ Time } & \multirow[b]{2}{*}{ Baseline } & \multirow[b]{2}{*}{ ISCI } & \multirow[b]{2}{*}{ REP1 } & \multirow[b]{2}{*}{ ISC2 } & \multirow[b]{2}{*}{ REP2 } & \multirow[b]{2}{*}{ ISC3 } & \multirow[b]{2}{*}{ REP3 } & \multirow[b]{2}{*}{ ISC4 } & \multirow[b]{2}{*}{ REP4 } & \multicolumn{3}{|c|}{ Recovery period } \\
\hline & & & & & & & & & & 60 & 120 & 180 \\
\hline Heart rate & 231 & 233 & 234 & 237 & 236 & 233 & 232 & 236 & 234 & 231 & 226 & 228 \\
\hline SEM & 6 & 5 & 5 & 7 & 7 & 9 & 8 & 8 & 6 & 8 & 10 & 10 \\
\hline Mean aortic pressure & 82.1 & $69.2^{*}$ & 74.8 & $69.7^{*}$ & 74.2 & $65^{*}$ & 71.2 & $69.8^{*}$ & 73 & 76.2 & 78.4 & 80.7 \\
\hline SEM & 4.4 & 3.7 & 3.5 & 4.9 & 3.7 & 5.2 & 3.8 & 4 & 3.4 & 4.2 & 4.3 & 5 \\
\hline $\operatorname{EDL}(m m)$ & 8.03 & 8.06 & 8.2 & 7.9 & 8.31 & 8.25 & 8.45 & 8.22 & $8.49^{*}$ & $8.47^{*}$ & $8.15^{*}$ & $8.21^{*}$ \\
\hline SEM & 0.64 & 0.53 & 0.59 & 0.63 & 0.57 & 0.56 & 0.66 & 0.56 & 0.57 & 0.58 & 0.61 & 0.62 \\
\hline$\%$ baseline EDL & 100 & 100.6 & 103.4 & 100.1 & 104.2 & 103.8 & 105.9 & 103.3 & $106.4^{*}$ & $106.4^{*}$ & $105.3^{*}$ & $106^{*}$ \\
\hline SEM & 0 & 4.1 & 2.1 & 2.9 & 2.4 & 3.7 & 2.4 & 3.7 & 1.9 & 2.1 & 2.1 & 2 \\
\hline $\operatorname{ESL}(m m)$ & 7.14 & 8.08 & 7.15 & 8.1 & 7.64 & 8.44 & 7.76 & 8.48 & $7.74^{*}$ & $7.57^{*}$ & $7.36^{*}$ & $7.35^{*}$ \\
\hline SEM & 0.6 & 0.52 & 0.54 & 0.6 & 0.56 & 0.56 & 0.61 & 0.57 & 0.57 & 0.56 & 0.61 & 0.62 \\
\hline \% baseline ESL & 100 & 116.6 & 105.4 & 116.4 & 107.9 & 119.6 & 109.4 & 120.5 & $109^{*}$ & $106.9^{*}$ & $105.9^{*}$ & $105.5^{*}$ \\
\hline SEM & 0 & 4.3 & 1.5 & 3.5 & 2.4 & 4.9 & 2.5 & 4.4 & 2.2 & 2.4 & 2.7 & 2.3 \\
\hline$\%$ SS & 11 & $-1.8^{*}$ & 10.08 & $-2.64^{*}$ & 8.26 & $-3.04^{*}$ & 8.64 & $-3.23^{*}$ & 9.26 & 10.66 & 11.64 & 12.22 \\
\hline SEM & 0.8 & 1.1 & 1.03 & 1.37 & 1.15 & 1.15 & 1.43 & 1.26 & 1.03 & 1.05 & 1.43 & 1.53 \\
\hline \% baseline SS & 100 & $-19^{*}$ & 89.1 & $-26.9^{*}$ & 73.8 & $-29.9^{*}$ & 76.6 & $-35^{*}$ & 89.4 & 98.2 & 101.8 & 106.4 \\
\hline SEM & 0 & 12.1 & 8.7 & 15.4 & 8.2 & 13 & 13.5 & 14.9 & 7.2 & 9.1 & 8.1 & 8.5 \\
\hline
\end{tabular}

This table summarizes the functional results of four cycles of $5 \mathrm{~min}$ of ischemia (ISC) and reperfusion (REP). For the ischemic region, $\mathrm{EDL}=$ end-diastolic segment length; $\mathrm{ESL}=$ end-systolic length; $\mathrm{SS}=$ segmental shortening. ${ }^{*} P<0.05$ vs. baseline. 


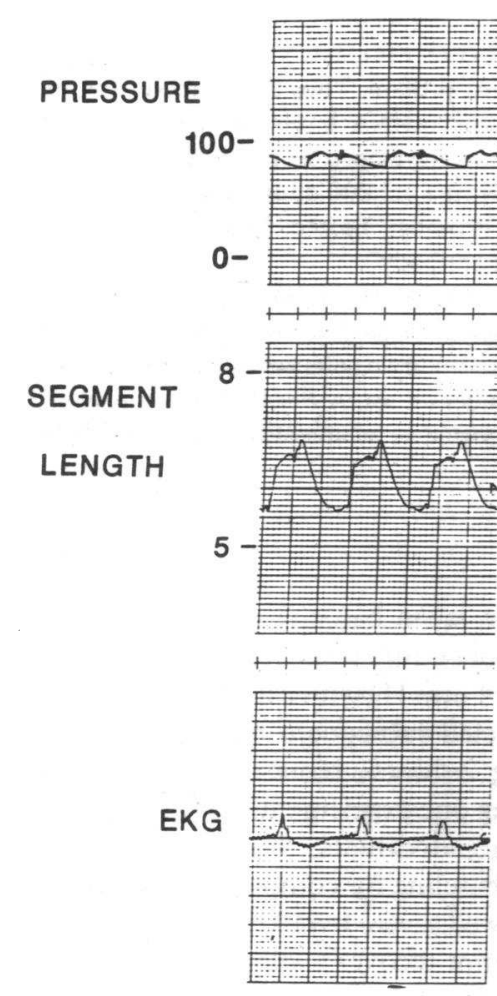

BASELINE

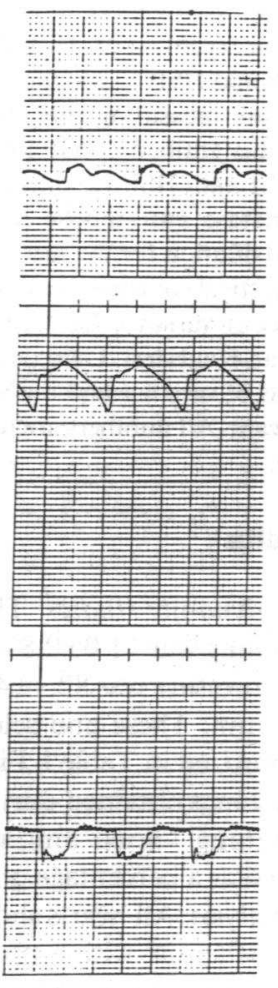

ISCHEMIA
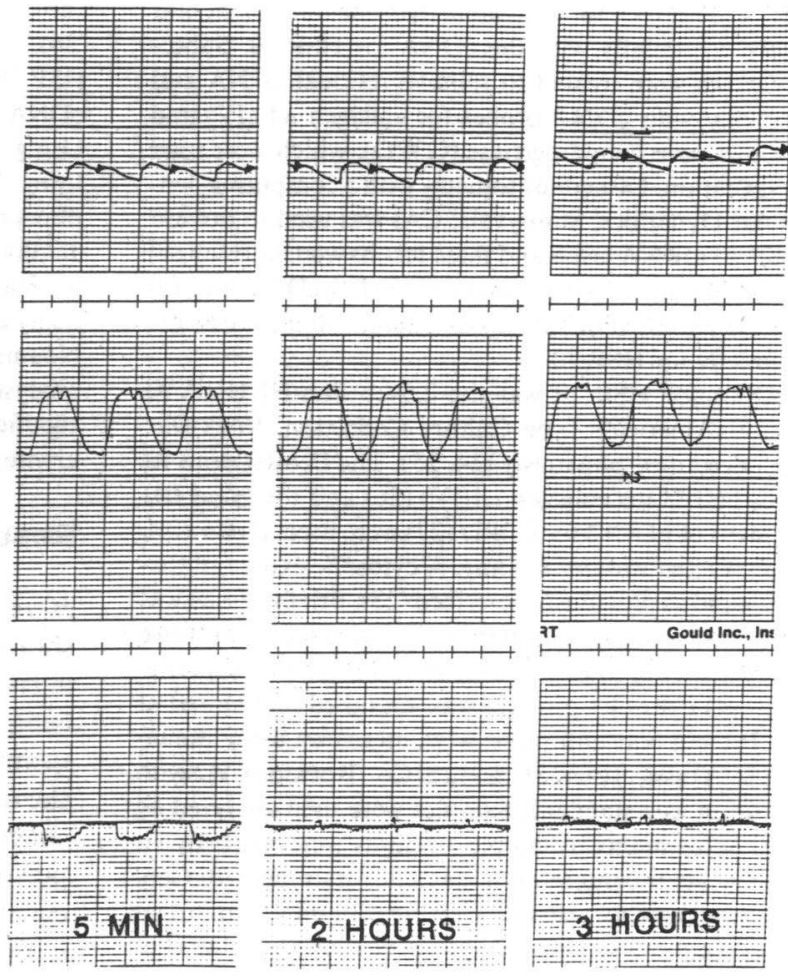

REPERFUSION

Figure 2. Representative tracings from the recorder illustrating observed changes. The top row shows the arterial pressure tracing (millimeters of $\mathrm{Hg}$ ). The second row shows segment length recordings. Scale is in millimeters. The bottom row shows an intramyocardial electrocardiogram recorded from the implanted piezoelectric crystals. The first set of panels demonstrates baseline recordings; the second set $4 \mathrm{~min} 45 \mathrm{~s}$ into the fourth period of ischemia; the third set $5 \mathrm{~min}$ of the fourth and final reperfusion, and the subsequent two sets of panels demonstrate 2 and $3 \mathrm{~h}$ of reperfusion. During ischemia, the end-diastolic length is increased, indicating ischemic segment elongation, and systolic shortening is reduced, indicating hypokinesis. During reperfusion, although percent segmental shortening is preserved, this is achieved by an increase in end-diastolic length. The increase in end-diastolic length persists throughout recovery.

line (Fig. 4). End-systolic length increased with each period of ischemia, and decreased with reperfusion (Fig. 4, top). Enddiastolic length increased with each reperfusion and by the final reperfusion was $106.4 \%$ of baseline $(P<0.05$, Fig. 4 , bottom). With each successive ischemic episode the end-systolic

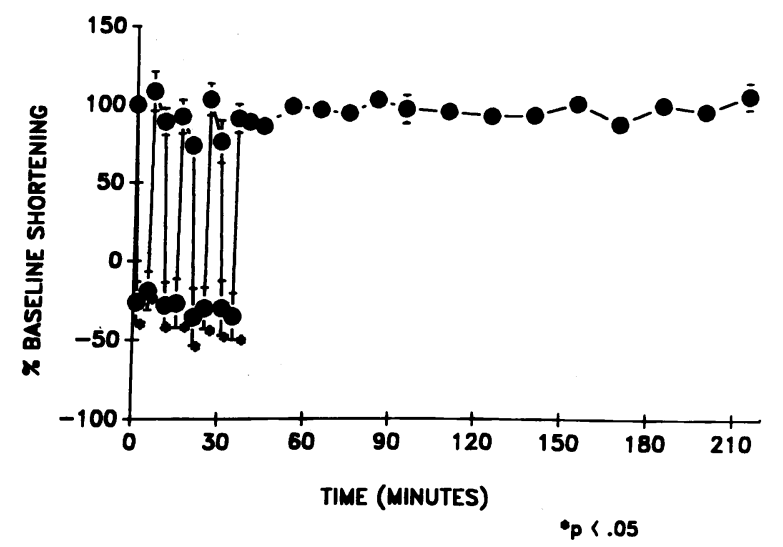

Figure 3. Systolic segmental shortening, as a percentage of baseline, calculated by the equation: $(E D L-E S L) / E D L \times 100=\% S S$. Segmental shortening was significantly less than baseline $(P<0.05)$ during the four ischemic periods as indicated by the asterisks. length increased and reached $120.5 \%$ of baseline by the end of the fourth period of ischemia ( $P<0.05$ vs. baseline). During recovery, $3 \mathrm{~h}$ after the fourth period of ischemia, both end-diastolic and end-systolic length were persistently elevated, and were $106 \pm 2$ and $105.5 \pm 2 \%$ of baseline, respectively, after $3 \mathrm{~h}$ of reperfusion.

In contrast to the changes in segment length observed in the ischemic region, the measurements made in the nonischemic regions $(n=2)$ showed an increase in end-diastolic length of $2-7 \%$ of baseline with ischemia whereas the end-systolic length remained unchanged and segmental shortening increased. During the 3-h recovery period end-diastolic length decreased to $92-99 \%$ of baseline. End-systolic length varied similarly.

The velocity of shortening, $\mathrm{d} L / \mathrm{d} t$, was reduced after repetitive ischemia in the ischemic region. At $5 \mathrm{~min}$ after the final reperfusion $\mathrm{d} L / \mathrm{d} t$ was $73.2 \pm 7.2 \%$ of baseline $(P<0.05) . \mathrm{d} L / \mathrm{d} t$ increased to $79.4 \pm 8.4 \%$ of baseline at $1 \mathrm{~h}$, and $83.5 \pm 10.3 \%$ at 3 h of reperfusion $(P<0.05$ for both values).

As shown in Table $I$, mean heart rate varied between $226 \pm 10.0$ and $237 \pm 7$ beats/min during the protocol. The mean aortic pressure ranged from $65 \pm 5.2$ to $82.1 \pm 4.4 \mathrm{~mm} \mathrm{Hg}$. Mean pressure decreased $8-12 \mathrm{~mm} \mathrm{Hg}$ with each ischemic episode $(P<0.05)$, and returned to baseline with reperfusion. There was no significant change in heart rate during the protocol. 

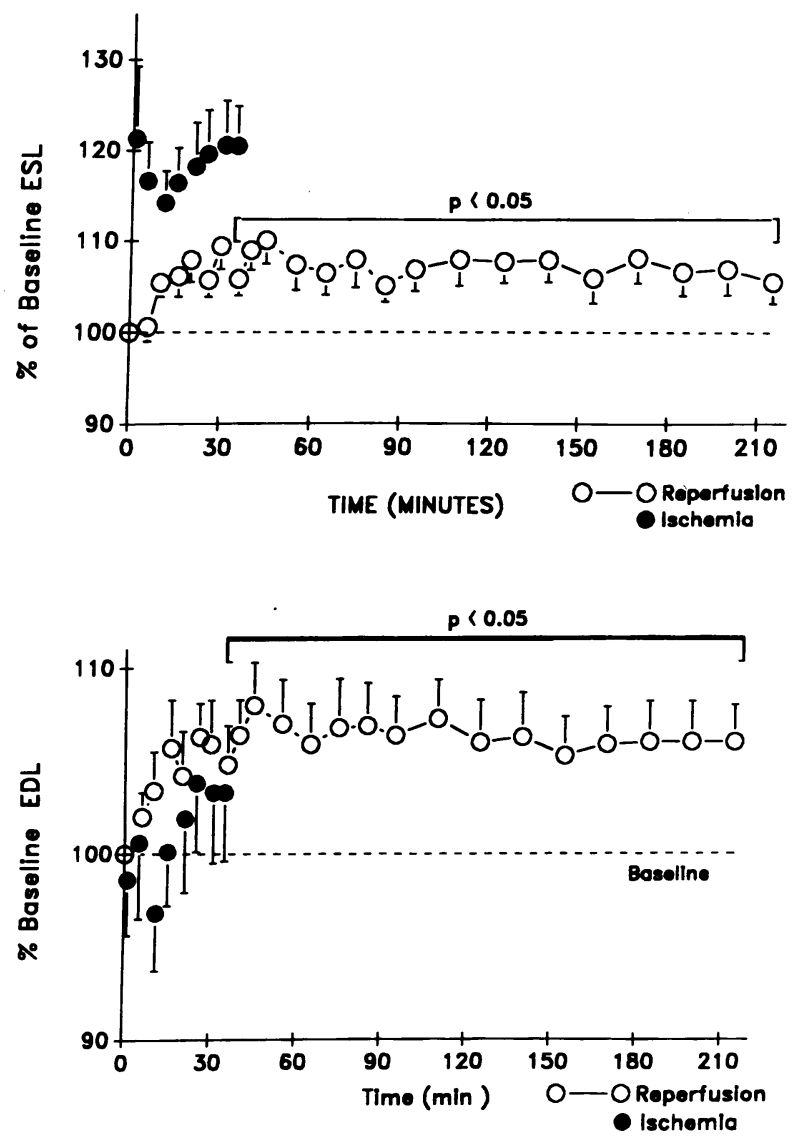

Figure 4. (Top) End-systolic length and (bottom) end-diastolic length expressed as percentage of baseline.

At the completion of the protocol the hearts were sliced and stained with nitroblue tetrazolium. The two rabbits, in which there had been technical difficulty implanting the crystals with obvious localized occlusion of an arterial branch in one case and perforation of an arterial branch in the other, both had infarcts distal to the crystal sites. These two rabbits were excluded from analysis. In the other 10 rabbits there was no evidence of infarct in the area of ischemia.

HSP 70 expression. Both a single 5-min coronary occlusion

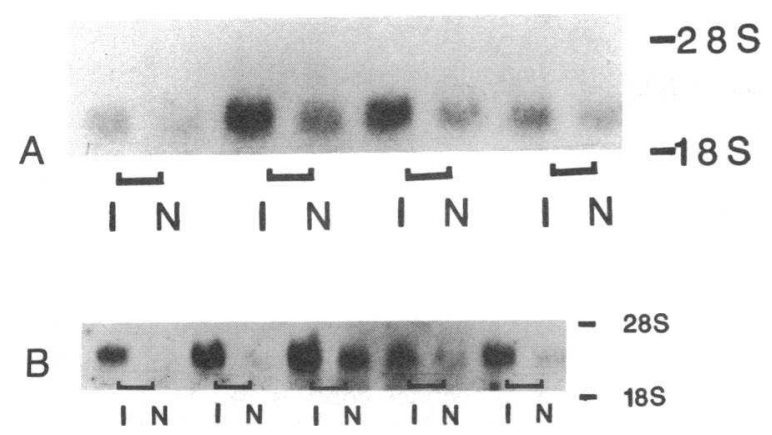

Figure 5. Northern blot analysis showing increase in HSP 70 expression $2 \mathrm{~h}$ after $(A)$ a single 5-min coronary occlusion or $(B)$ four cycles of $5 \mathrm{~min}$ of ischemia/5 min of reperfusion. Individual hearts are shown in pairs of ischemic $(I)$ and nonischemic $(N)$ areas from the same heart. Equivalence of RNA applied to lanes was confirmed by visual inspection. and repetitive occlusion and reperfusion significantly increased the steady-state level of HSP 70 mRNA over the baseline constitutive expression as determined by Northern blotting (Fig. 5). Compared with the nonischemic tissue from the same hearts, a single 5-min occlusion increased the amount of HSP 70 mRNA expressed by a factor of $1.8(n=4, P<0.04)$ as determined by densitometric analysis (Fig. $5 \mathrm{~A}$ ). Repetitive ischemia with four 5-min occlusions resulted in a 2.3-fold increase compared with nonischemic tissue from the same ventricle ( $n$ $=5, P=0.006$ ) shown in Fig. $5 B$.

The time course for the increase in HSP $70 \mathrm{mRNA}$ in the ischemic region after repetitive ischemia is shown in Fig. $6 \mathrm{~A}$. HSP 70 mRNA levels were increased as early as $1 \mathrm{~h}$ after the final reperfusion in the repetitive ischemia group, and this increase persisted to $4 \mathrm{~h}$. By $24 \mathrm{~h}$ steady-state mRNA levels had returned to baseline. To quantitate changes in mRNA, all samples from the repetitive ischemia protocol, and four samples of RNA from normal rabbit hearts were compared using dot blot analysis. Densitometric quantitation for HSP 70 was then nor-

A HSP 70
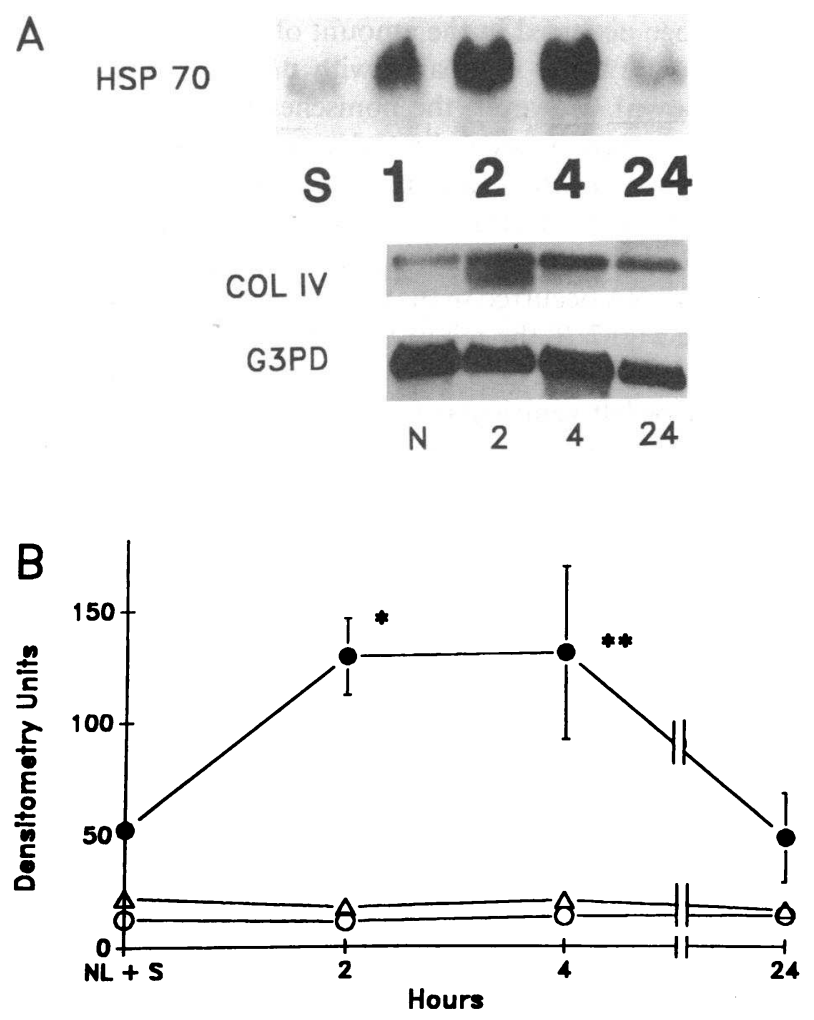

Figure 6. $(A)$ Northern blot analysis showing time course of increased expression of HSP $70 \mathrm{mRNA}$ after four cycles of $5 \mathrm{~min}$ of ischemia/5 min of reperfusion. Increase seen as early as $1 \mathrm{~h}$ and persisting up to $4 \mathrm{~h}$ after completion of protocol. By $24 \mathrm{~h}$ levels have returned to baseline. S, sham-operated control. 1, 2, 4, and 24 represent hours after completion of protocol. $\mathrm{Col} \mathrm{IV}$, Northern blot showing expression of collagen $\alpha 1$ (IV) in normal heart $(N)$ and 2,4 , and 24 $\mathrm{h}$ after repetitive ischemia. G3PD, Same Northern blot as shown for collagen $\alpha 1$ (IV) hybridized with G3PD. (B) Densitometric analysis of HSP $70(\bullet)$, G3PD (O), and collagen $\alpha 1$ (IV) ( $\Delta)$. Results are \pm SEM. Standard error bars are not visible for some data points because markers are smaller than data symbol. For clarity the relative values for G3PD and collagen $\alpha 1$ (IV) were reduced by a factor of 10 . Collagen $\alpha 1$ (IV) showed a maximum variation of $11 \%$ while G3PD showed a maximum variation of $25 \%$. ${ }^{*} P<0.001 .{ }^{* *} P=0.018$ vs. normals + shams. 
malized to the results for collagen $\alpha 1$ (IV) and for G3PD, protein localized to the extracellular matrix and cytosol, respectively, as described under Methods. Preliminary studies, shown in Fig. $6 \mathrm{~A}$, indicated that collagen $\alpha 1$ (IV) and G3PD mRNA do not undergo marked change during the experimental treatment in this study. The densitometry results, illustrated in Fig. $6 \mathrm{~B}$, confirmed the marked increase in HSP 70 mRNA by $2 \mathrm{~h}$ $(P<0.001)$. Normalization of this data to either of the two control mRNAs established a threefold increase in HSP 70 mRNA compared with normal and sham hearts. This increase persisted at $4 \mathrm{~h}(P=0.018)$, but had returned to normal by 24 $\mathrm{h}$. In the hearts subjected to coronary occlusion for $2 \mathrm{~h} 35 \mathrm{~min}$, matching the total protocol duration for the 2-h repetitive ischemia group, HSP 70 mRNA increased 6.5-8.5-fold when normalized to collagen $1 \alpha$ (IV) or G3PD, respectively (data not shown).

HSP 70 mRNA expression in the nonischemic tissue samples from ventricles of the hearts subjected to repetitive ischemia were compared with samples from normal, untreated hearts and sham-operated controls. For the single 5-min occlusion no change occurred in the amount of HSP $70 \mathrm{mRNA}$ in the nonischemic tissue compared with normal myocardium (data not shown). However, the nonischemic tissue from the repetitive occlusion protocol showed a twofold increase in expression compared with sham-operated controls (Fig. $7 \mathrm{~A}$ ).

The localization of HSP 70 mRNA in the normal rabbit heart was examined to determine if differences in the amount of HSP 70 mRNA occurred in the different regions of the heart. As shown in Fig. $7 \mathrm{~B}$, the relative amount of HSP $70 \mathrm{mRNA}$ was similar in the atria (left and right combined), right ventricle, septum, or left ventricular free wall.

Direct visualization of different isoforms of HSP 70 protein in homogenates of cardiac tissue was performed by immunodetection after two-dimensional gel electrophoresis. As illustrated in Fig. 8, as early as $2 \mathrm{~h}$ after repetitive ischemia/reperfusion there was an increase both in the amount and the number of immunoreactive isoforms. The most apparent change was an increase in the amount of the more basic isoforms, which was clearly visualized both at 4 and $24 \mathrm{~h}$ after repetitive ischemia. These proteins, corresponding to the inducible members of the HSP 70 family, were barely detectable in control tissues, but were clearly visible in samples which underwent repetitive ischemia and reperfusion. Increases in the more acidic constitutive form also were evident.

\section{Discussion}

These studies provide new information on the mechanical changes in an in vivo rabbit heart model of stunning and show that changes in gene expression accompany the functional changes. The functional studies demonstrate that in the rabbit in vivo production of brief repetitive myocardial ischemia resulted in a mild stunning characterized by an increased enddiastolic and end-systolic length with preservation of fractional shortening. End-systolic length increased significantly with each ischemic episode secondary to bulging of the ischemic wall. With each ischemia/reperfusion cycle, end-diastolic and end-systolic length gradually increased until they were significantly different from baseline $5 \mathrm{~min}$ into the final recovery period. Although the degree to which these values were increased lessened during the $3 \mathrm{~h}$ of recovery, they remained significantly elevated throughout. $\mathrm{d} L / \mathrm{d} t$ was depressed after repetitive ischemia. These findings are consistent with an increase in preload (end-diastolic length) to maintain function (segmental shortening) in the face of decreased contractility (increased end-systolic length). In contrast, no increase in enddiastolic or end-systolic length occurred in the nonischemic myocardium during recovery. This combination of an increase in end-diastolic length and end-systolic length with preservation of segmental shortening, but with a reduced velocity of shortening $(\mathrm{d} L / \mathrm{d} t)$ and the absence of necrosis by nitroblue tetrazolium staining represents mild myocardial stunning. Although segment length and segmental shortening increased in the nonischemic myocardium during the ischemic periods, these changes resolved after reperfusion.

The functional changes in the present study are similar to
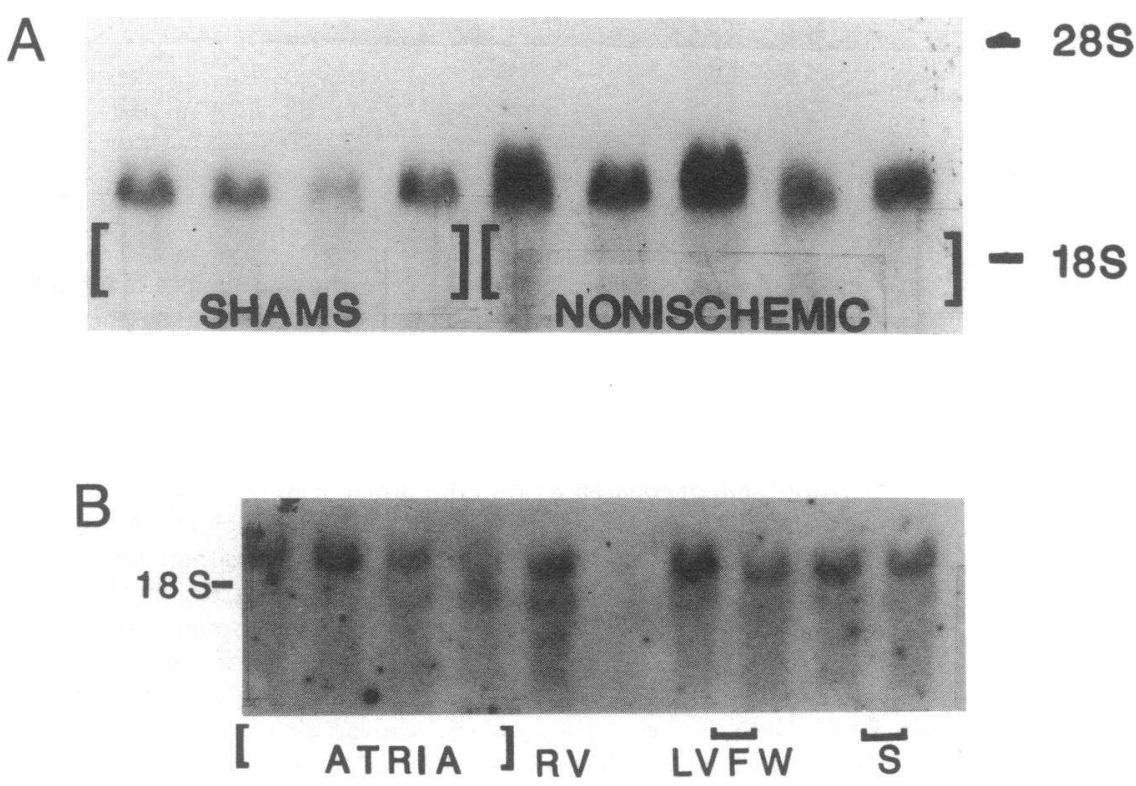

Figure 7. $(A)$ Northern blot analysis showing increased HSP 70 expression in nonischemic area of the ventricle $2 \mathrm{~h}$ after repetitive ischemia/reperfusion compared with shamoperated controls. Hearts were removed from sham-operated controls after the same duration of time as the 2-h repetitive ischemia/reperfusion group, including time for the protocol. $(B)$ Northern blot demonstrating equal distribution of HSP 70 in the normal left ventricular free wall $(L V F W)$, septum $(S)$, right ventricle $(R V)$, and atria. 

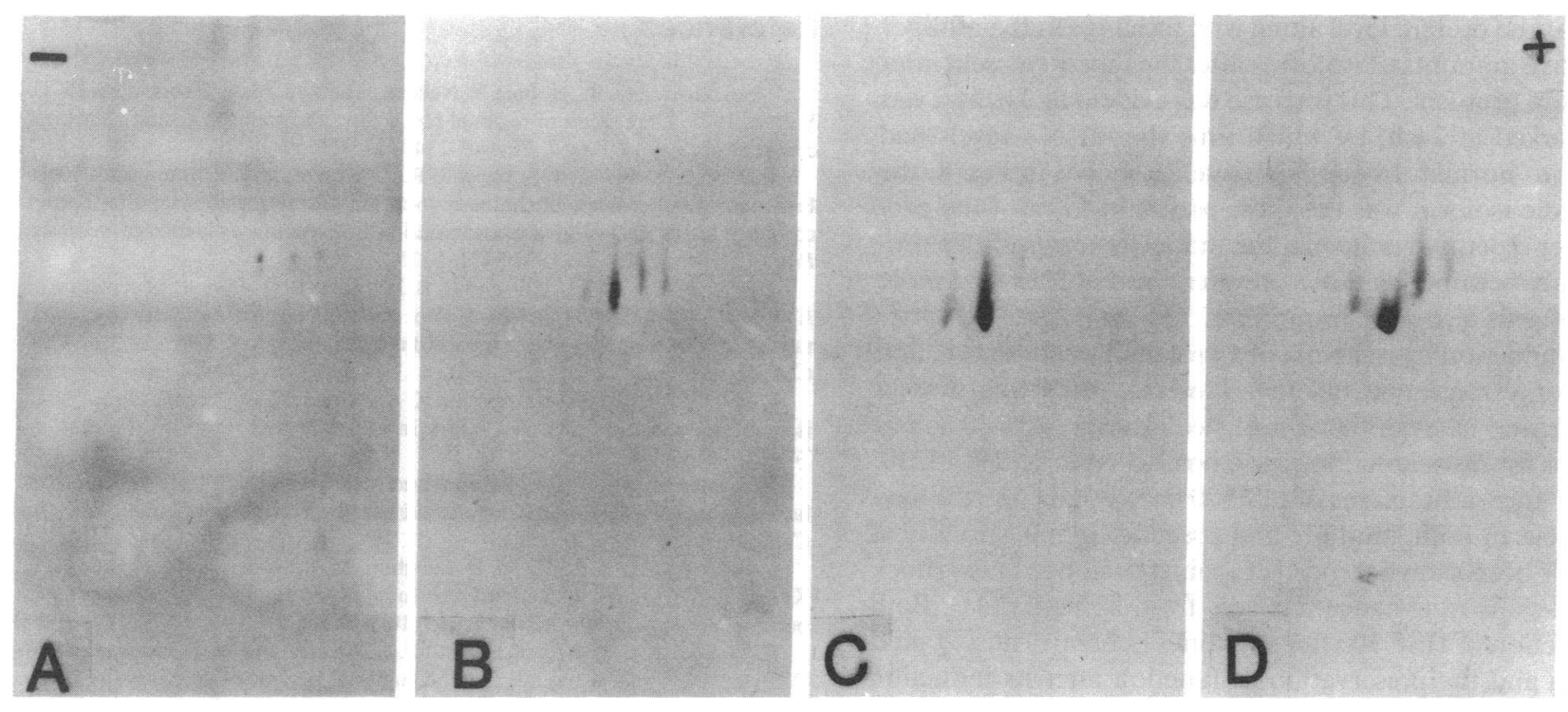

Figure 8. Representative two-dimensional Western blot analyses of two-dimensional gels illustrating HSP 70 expression in the rabbit myocardium after repetitive ischemia. Tissue extracts were subjected to two-dimensional gel electrophoresis and transferred to nitrocellulose for Western blot analysis using HSP 70 (72) antibody. $(A)$ Normal myocardium. Four sham-operated controls showed similar results. $(B) 2 \mathrm{~h},(C)$ $4 \mathrm{~h}$, and $(D) 24 \mathrm{~h}$ after repetitive ischemia. Each blot represents one example out of two to four similar blots for each time point.

those reported by Heyndrickx and co-workers $(1,31)$. In these studies, which first reported the depression in myocardial function following transient ischemia, an increase in end-diastolic and end-systolic length was observed after a single 5- or 15-min occlusion of the canine left anterior descending coronary. These changes persisted for $3 \mathrm{~h}$ after a single 5-min occlusion and for $>6 \mathrm{~h}$ after a $15-\mathrm{min}$ occlusion. Using subendocardial crystals Lange et al. (32) observed no lasting increase in segment length, but did observe prolonged depression of segment shortening after three 5-min or three 15-min coronary occlusions in the dog. The differences between these findings and our own could be attributed to placement of the crystals, which were localized midwall in the current study. Other studies suggesting that the subendocardium is more susceptible to ischemia than the subepicardium, would indicate that more profound abnormalities occur in the subendocardium after brief ischemia (33-35). However, given the small size of the rabbit heart, it is technically difficult to place piezoelectric crystals in the subendocardium. Investigators have observed prolonged abnormalities of wall thickening after brief ischemia in the dog, and this may be a more sensitive index of dysfunction than segmental shortening $(1,36)$. Others have shown very prolonged depression of segmental shortening after ischemia of 2-h duration or longer in the $\operatorname{dog}(37,38)$. This dysfunction, which was accompanied by evidence of subendocardial necrosis, likely reflects a different phenomena, where the subepicardium is recruited to perform more work secondary to the irreversible damage in the subendocardial level, and is not comparable to the very mild ischemia which we used in our protocols.

In previous studies from our laboratory much more severe mechanical stunning had been reported after the same repetitive ischemia protocol in the isolated blood-perfused rabbit heart (18). One important difference between the two studies is that the ischemia in the isolated heart was global, eliminating the collateral flow, which amounts to $10-12 \%$ of baseline circulation in the in vivo coronary ligation model (39).
These experiments demonstrate that alterations in gene expression, specifically an increase in HSP 70, were induced by a brief episode of ischemia, simulating the clinical condition of angina. A single 5-min coronary occlusion nearly doubled the steady-state level of HSP 70 mRNA, and with multiple occlusions, the experimental equivalent of unstable angina, HSP 70 mRNA levels were increased approximately threefold. The observed increase in HSP 70 mRNA was transient, occurring as early as $1 \mathrm{~h}$ after reperfusion and returning to control levels by $24 \mathrm{~h}$. Furthermore, not only did the area of ischemia show a change in gene expression, but the nonischemic region of the ventricle also changed, though to a smaller degree. After a single coronary occlusion no change was detected in the nonischemic ventricle, but after four coronary occlusions this region of the ventricle had a twofold increase in HSP 70 mRNA. Thus brief anginal episodes are sufficient to change gene expression not only in the zone of ischemia, but also in the nonischemic tissue. In contrast, $2 \mathrm{~h} 35 \mathrm{~min}$ of ischemia without reperfusion resulted in a 6.5-8.5-fold increase in HSP 70 mRNA. This suggests that there is a graduated response to ischemia. Although brief ischemia resulted in a marked increase HSP 70 mRNA, more severe ischemia resulted in an even greater increase.

The mechanisms responsible for the altered HSP expression in the ischemic and nonischemic regions of the heart may reflect a relationship between the metabolic consequences of ischemia (i.e., tissue acidosis and hypoxia) and its mechanical effects. The nonischemic ventricle during ischemia would have had increased contractile work secondary to the increased load resulting from the severe hypokinesis and dyskinesis of the ischemic zone. Such an increased workload, or possibly an increased left ventricular end-diastolic pressure, may have resulted in the modest increase in HSP 70 expression in the nonischemic ventricle similar to acute pressure overload, which has been shown to increase HSP 70 expression $(12,13)$.

Western blotting procedures demonstrated an increase in 
HSP 70 at the protein level along with a change in the number and relative amounts of isoforms after the repetitive ischemia/ reperfusion protocol. This increase was evident at $2 \mathrm{~h}$, and was more marked at $24 \mathrm{~h}$, by which time the mRNA levels had returned to normal. In control tissue, as shown in Fig. 8, the most acidic isoform was the most prevalent form of the protein. After repetitive ischemia, the inducible forms of this protein family became far more prevalent and at least two more basic isoforms also were prominent.

The induction by ischemia of a protein thought to function by blocking translation of other proteins, protecting protein structure, and associating with nucleoli during stress, has implications for myocardial function postischemia $(9,10,15,30$, 40). The known functions of HSP 70 suggest this protein may have a role in both stunning and preconditioning. Brief heat shock has been shown to protect against prolonged heat shock (40) as well as to enhance recovery from ischemia (41). Both the induction of HSP 70 after very brief ischemia causing mild stunning and the preservation of function after its induction make it a strong candidate to contribute to the well-described conditioning effect of Murray et al. (4). This same preconditioning has recently been reported in the rabbit (42). Further studies need to be done to determine if HSP 70 induction before ischemia can have a protective or preconditioning effect in the heart.

The only previous reports of HSP 70 induction in the heart involved prolonged heat shock or ischemia of long enough duration to produce cell death $(11,43,44)$. Furthermore, although well-described in the canine model, myocardial stunning has not been previously described in the rabbit in vivo. In our studies we found mild stunning characterized by upward movement on the Starling curve which persisted for $3 \mathrm{~h}$. A single 5-min period of ischemia in the rabbit was sufficient to induce expression of HSP 70, and repetitive ischemia increased the expression. In the absence of further ischemia this was a transient response with resolution of the increase in HSP 70 mRNA by $24 \mathrm{~h}$, although an increase in HSP 70 at the protein level was still present at $24 \mathrm{~h}$. We have shown the alteration of protein expression occurs in an experimental model that produces mild postischemic dysfunction, and suggest it may play a role in the persistent abnormalities observed after transient ischemia. The suppression of the translation of other mRNAs by HSP 70 could prevent the resynthesis of important regulatory proteins. For example, the persistent abnormalities of purine metabolism after transient ischemia in the canine heart (2) might be explained by reduced synthesis of enzymes involved in purine metabolism. If HSP 70 is protective, as experiments so far indicate $(10,40,41,45)$, regulation of HSP 70 has implications both for understanding the various ischemic conditions associated with coronary artery disease, as well as for the induced ischemia of cardioplegia.

\section{Acknowledgments}

The authors gratefully acknowledge the expert advice and assistance of Dr. W. Mark Vogel and Dr. Carolyn M. Connelly with the functional studies.

This study was supported by research grants HL-31195 (Dr. Brecher) and HL-38189 (Dr. Apstein) from the National Institutes of Health. Dr. Knowlton is the recipient of Physician Scientist Award HL-01853.

\section{References}

1. Heyndrickx, G. R., H. Baig, P. Nellens, I. Leusen, M. C. Fishbein, and S. F. Vatner. 1978. Depression of regional blood flow and wall thickening after brief coronary occlusions. Am. J. Physiol. 234:H653-H659.

2. DeBoer, L. W. V., J. S. Ingwall, R. A. Kloner, and E. Braunwald. 1980. Prolonged derangements of canine myocardial purine metabolism after a brief coronary artery occlusion not associated with anatomic evidence of necrosis. Proc. Natl. Acad. Sci. USA. 77:5471-5475.

3. Reimer, K. A., M. L. Hill, and R. B. Jennings. 1981. Prolonged depletion of ATP and of the adenine nucleotide pool due to delayed resynthesis of adenine nucleotides following reversible myocardial ischemic injury in dogs. J. Mol. Cell. Cardiol. 13:229-239.

4. Murry, C. E., R. B. Jennings, and K. A. Reimer. 1986. Preconditioning with ischemia: a delay of lethal cell injury in ischemic myocardium. Circulation. 74:1124-1136.

5. Taegtmeyer, H., A. F. C. Roberts, and A. E. G. Raine. 1985. Energy metabolism in reperfused heart muscle: metabolic correlates to return of function. J. Am. Coll. Cardiol. 6:864-870.

6. Schroder, E., R. A. Kieso, D. Laughlin, M. Schroder, R. Meng, and R. E. Kerber. 1987. Altered response of reperfused myocardium to repeated coronary occlusion in dogs. J. Am. Coll. Cardiol. 10:898-905.

7. Weiner, J., C. S. Apstein, J. Arthur, F. Pirzada, and W. B. Hood, Jr. 1976. Persistance of myocardial injury following brief periods of coronary occlusion. Cardiovas. Res. 10:678-686.

8. Braunwald, E., and R. A. Kloner. 1982. The stunned myocardium: prolonged, postischemic ventricular dysfunction. Circulation. 66:1146-1149.

9. Lindquist, S., and E. A. Craig. 1988. The heat-shock proteins. Annu. Rev. Genet. 22:631-677.

10. Welch, W. J. 1987. The mammalian heat shock (or stress) response: a cellular defense mechanism. Adv. Exp. Med. Biol. 225:287-304.

11. Dillman, W. H., H. B. Mehta, A. Barrieux, B. D. Guth, W. E. Neeley, and J. Ross. 1986. Ischemia of the dog heart induces the appearance of a cardiac mRNA coding for a protein with migration characteristics similar to heat-shock/ stress protein 71. Circ. Res. 59:110-114.

12. Delcayre, C., J.-L. Samuel, F. Marotte, M. Best-Belpomme, J. J. Mercadier, and L. Rappaport. 1988. Synthesis of stress proteins in rat cardiac myocytes 2-4 days after imposition of hemodynamic overload. J. Clin. Invest. 82:460-468.

13. Izumo, S., B. Nadal-Ginard, and V. Mahdavi. 1988. Protooncogene induction and reprogramming of cardiac gene expression produced by pressure overload. Proc. Natl. Acad. Sci. USA. 85:339-343.

14. Milarski, M. L., W. J. Welch, and R. I. Morimoto. 1989. Cell cycle-dependent association of HSP 70 with specific cellular proteins. J. Cell Biol. 108:413423.

15. Lindquist, S. 1980. Translational efficiency of heat-induced messages in Drosophila melanogaster cells. J. Mol. Biol. 137:151-158.

16. Schulz, R., S. Miyazaki, M. Miller, E. Thaulow, G. Heusch, J. Ross Jr. and B. D. Guth. 1989. Consequences of regional inotropic stimulation of ischemic myocardium on regional blood flow and function in the anesthetized swine. Circ. Res. 64:1116-1126.

17. Kusuoka, H., J. K. Porterfield, H. F. Weisman, M. L. Weisfeldt, and E Marban. 1987. Pathophysiology and pathogenesis of stunned myocardium. $J$. Clin. Invest. 79:950-961.

18. Owen, A. N., W. N. Grice, W. M. Vogel, and C. S. Apstein. 1989. Improved diastolic function during repetitive ischemia and reperfusion by beta adrenergic stimulation. J. Mol. Cell. Cardiol. 21:S.21.

19. Connelly, C. M., W. M. Vogel, Y. M. Hernandez, and C. S. Apstein. 1982. Movement of necrotic wavefront after coronary artery occlusion in rabbit. Am. J. Physiol. 243:H682-H690.

20. Foster, E., D. DeJong, C. M. Connelly, and C. S. Apstein. 1984. Failure of nifedipine and reperfusion to reduce infarct size relative to region at risk as measured by NADH fluorophotography. Circulation. 70:506-512.

21. Schaper, W. 1984. Experimental Infarcts and the Microcirculation. In Therapeutic Approaches to Myocardial Infarct Size Limitation. D. J. Hearse and D. M. Yellon, editors. Raven Press, New York. 79-90.

22. Chirgwin, J. M., A. E. Przbyla, R. J. MacDonald, and W. J. Rutter. 1979. Isolation of biologically active ribonucleic acid from sources enriched in ribonuclease. Biochemistry. 18:5294-5299.

23. Sarzani, R., K. Claffey, A. V. Chobanian, and P. Brecher. 1988. Hypertension induces tissue-specific gene suppression of a fatty acid binding protein in rat aorta. Proc. Natl. Acad. Sci. USA. 85:7777-7781.

24. Wu, B., C. Hunt, and R. I. Morimoto. 1985. Structure and expression of the human gene encoding major heat shock protein HSP 70. Mol. Cell. Biol. $5: 330-341$.

25. Hunt, C, and R. I. Morimoto. 1985. Conserved features of eukaryotic HSP 70 genes revealed by comparison with the nucleotide sequence of human HSP 70. Proc. Natl. Acad. Sci. USA. 82:6455-6459.

26. Kurkinen, M., M. R. Condon, B. Blumberg, D. P. Barlow, S. Quinones, J. 
Saus, and T. Pihlajaniem. 1987. Extensive homology between the carboxyl-terminal peptides of mouse $\alpha 1$ (IV) and $\alpha 2$ (IV) collagen. J. Biol. Chem. 262:84968499.

27. Tso, J. Y., X.-H. Sun, T. Kao, K.S. Reece, and R. Wu. 1985. Isolation and characterization of rat and human glyceraldehyde-3-phosphate dehydrogenase cDNAs: genomic complexity and molecular evolution of the gene. Nucleic Acids Res. 13:2485-2502.

28. Knowlton, A. A., R. E. Burrier, and P. Brecher. 1989. Rabbit heart fatty acid binding protein: isolation, characterization, and application of a monoclonal antibody. Circ. Res. 65:981-988.

29. Welch, W. J., and J. P. Suhan. 1986. Cellular and biochemical events in mammalian cells during and after recovery from physiological stress. J. Cell Biol. 103:2035-2052.

30. Welch, W. J., and J. R. Feramisco. 1984. Nuclear and nucleolar localization of the 72,000-dalton heat shock protein in heat-shocked mammalian cells. $J$. Biol. Chem. 259:4501-4513.

31. Heyndrickx, G. R., R. W. Millard, R. J. McRitchie, P. R. Maroko, and S. F. Vatner. 1975. Regional myocardial functional and electrophysiological alterations after brief coronary artery occlusion in conscious dogs. J. Clin. Invest. 56:978-985.

32. Lange, R., J. Ware, and R. A. Kloner. 1984. Absence of cumulative deterioration of regional function during three repeated 5 or 15 minute coronary occlusions. Circulation. 69:400-408.

33. Sabbah, H. N., M. Marzilli, and P. D. Stein. 1981. The relative role of subendocardium and subepicardium in left ventricular mechanics. Am. J. Physiol. 240:H920-H926.

34. Gallagher, K. P., M. C. Stirling, M. Choy, C. A. Szpunar, R. A. Gerren, M. J. Botham, and J. H. Lemmer. 1985. Dissociation between epicardial and transmural function during acute myocardial ischemia. Circulation. 71:12791291.

35. Bolli, R., B. S. Patel, C. J. Hartley, J. I. Thornby, M. O. Jeroudi, and R.
Roberts. 1989. Nonuniform transmural recovery of contractile function in stunned myocardium. Am. J. Physiol. 257:H375-H385.

36. Bolli, R., W. Zhu, J. I. Thornby, P. G. O'Neill, and R. Roberts. 1988. Time course and determinants of recovery of function after reversible ischemia in conscious dogs. Am. J. Physiol. 254:H102-H114.

37. Ellis, S. G., J. Wynne, E. Braunwald, C. I. Henschke, T. Sandor, and R. A. Kloner. 1984. Response of reperfusion-salvaged, stunned myocardium to inotropic stimulation. Am. Heart J. 107:13-19.

38. Bush, L. R., L. M. Buja, W. Samowitz, R. E. Rude, M. Wathen, G. D. Tilton, and J. T. Willerson. 1983. Recovery of left ventricular segmental function after long-term reperfusion following temporary coronary occlusion in concious dogs. Comparison of 2- and 4-hour occlusions. Circ. Res. 53:248-263.

39. Connelly, C. M., J. A. Leppo, P. W. Weitzman, W. M. Vogel, and C. S Apstein. 1989. Effect of coronary occlusion and reperfusion on myocardial blood flow during infarct healing. Am. J. Physiol. 257:H365-H374.

40. Burdon, R. H. 1986. Heat shock and the heat shock proteins. Biochem. J. 240:313-324.

41. Currie, R. W., M. Karmazyn, M. Kloc, and K. Mailer. 1988. Heat-shock response is associated with enhanced postischemic ventricular recovery. Circ. Res. 63:543-549.

42. Downey, J. M., and M. Jordan. 1989. Preconditioning limits infarct size in rabbits. Circulation. 80:11-238.

43. Mehta, H. B., B. K. Popovich, and W. H. Dillmann. 1988. Ischemia induces changes in the level of mRNAs coding for stress protein 71 and creatine kinase M. Circ. Res. 63:512-517.

44. Currie, R. W. 1987. Effects of ischemia and perfusion temperature on the synthesis of stress-induced (heat shock) proteins in isolated and perfused rat hearts. J. Mol. Cell. Cardiol. 19:795-808.

45. Edington, B. V., S. A. Whelan, and L. E. Hightower. 1989. Inhibition of heat shock (stress) protein induction by deuterium oxide and glycerol: additional support for the abnormal protein hypothesis of induction. J. Cell. Physiol. 139:219-228. 